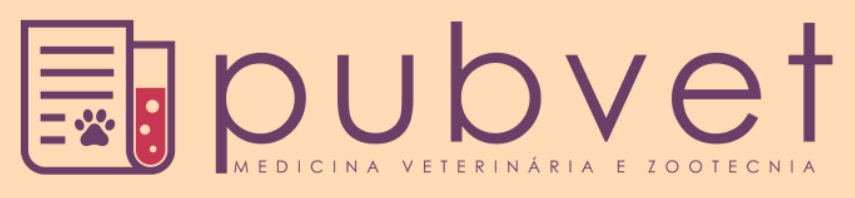

HTTP://DX.DOI.ORG/10.22256/PUBVET.V11N12.1227-1232

\title{
Exostose cartilaginosa múltipla: Relato de caso
}

\section{Eduarda Aléxia Nunes Louzada Dias ${ }^{1 *}$, Guilherme Albuquerque de Oliveira Cavalcanti ${ }^{2}$, Letícia Fernandes Pereira ${ }^{3}$}

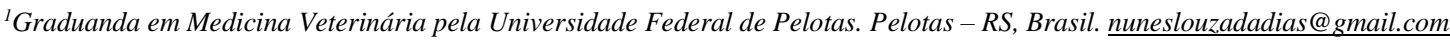

${ }^{2}$ Professor Adjunto da Universidade Federal de Pelotas, Departamento de Clínicas Veterinária. Pelotas - RS, Brasil.guialbuquerque@yahoo.com

${ }^{3}$ Médica Veterinária, Pelotas - RS, Brasil.letiiciafp@gmail.com

*Autor para correspondência

RESUMO. Foram atendidos dois cães da raça Teckel, ambos com histórico de dificuldade de locomoção e perda de propriocepção, sem alterações nos exames hemáticos. O primeiro cão, uma fêmea, de quatro meses de idade, apresentou ao exame radiográfico presença de massa radiopaca na metáfise distal do fêmur proximal e distal, da tíbia e proximal da fíbula esquerda; além de estruturas semelhantes nos processos espinhosos de T3, T6 e T7 e na terceira costela direita, projetando-se para o interior da cavidade torácica. O segundo cão, um macho de 6 meses de idade, apresentou massas ósseas nodulares no ísquio e ílio, e nas metáfises proximais de ambas as tíbias e distal da tíbia direita, além de alterações idênticas nas costelas, projetando-se, tanto para a superfície externa quanto interna do tórax. Portanto, após a análise radiográfica foi diagnosticado Exostose Cartilaginosa Múltipla (ECM), uma doença caracterizada por projeções ósseas recobertas por cartilagem. Adotouse como medida terapêutica o uso de tramadol e o acompanhamento da evolução da doença.

Palavras chave: Nódulo ósseo, osteocondroma, proliferação óssea

\section{Multiple cartilaginous exostosis: Case report}

ABSTRACT. This article reports the care of two dogs from Teckel race, both with a history of limited mobility and loss of proprioception, no changes in hematic tests. The first dog, a female, 4 months old, had to take radiographic presence of radiopaque mass at the distal femoral metaphysis, proximal and distal tibia and the proximal left fibula, and similar structures at the spinous processes of $\mathrm{T} 3, \mathrm{~T} 6$ and $\mathrm{T} 7$ and the third right rib, protruding into the chest cavity. The second dog, a male 6 months old, had nodular bone mass in the ischium and ilium, and proximal metaphysis of tibiae and distal right tibia, as well as similar changes in the ribs protruding both to the surface external and internal chest. Therefore, after the X-ray analysis was diagnosed multiple cartilaginous exostosis (ECM), a disease characterized by bone projections covered with cartilage. It was adopted as a therapeutic measure the use of tramadol and the monitoring of disease progression.

Keywords: Bone nodule, osteochondroma, bone proliferation

\section{Exostosis cartilaginosa múltiple: Reporte de caso}

RESUMEN. Se atendieron dos perros de la raza Teckel, ambos con historial de dificultad de locomoción y pérdida de propriocepción, sin alteraciones en los exámenes hemáticos. El primer perro, una hembra, de cuatro meses de edad, presentó al examen radiográfico presencia de masa radiopaca en la metáfisis distal del fémur proximal y distal, de la tibia y proximal de la fíbula izquierda; además de estructuras similares en los procesos espinosos de T3, T6 y T7 y en la tercera costilla derecha, proyectándose hacia el interior de la cavidad torácica. El segundo perro, un macho de 6 meses de edad, presentó masas óseas nodulares 
en el ísquio y el ílio, y en las metáfisis proximales de ambas tibias y distal de la tibia derecha, además de alteraciones idénticas en las costillas, proyectándose, tanto para la superficie externa como interna del tórax. Por lo tanto, después del análisis radiográfico se diagnosticó Exostosis Cartilaginosa Múltiple (ECM), una enfermedad caracterizada por proyecciones óseas recubiertas por cartílago. Se adoptó como medida terapéutica el uso de tramadol y el seguimiento de la evolución de la enfermedad.

Palabras clave: Nódulo óseo, osteocondroma, proliferación ósea

\section{Introdução}

A exostose cartilaginosa múltipla é um distúrbio do desenvolvimento ósseo que acomete animais jovens (Hameetman et al., 2004, Withrow et al., 2013) de diversas espécies e pode causar sinais clínicos, como dor e perda ou alteração da função das estruturas adjacentes, além de poder sofrer transformação maligna (Gambardella et al., 1975, Vanel et al., 2013, Withrow et al., 2013, Andersson, 2009).

A etiologia da ECM em cães ainda não está totalmente esclarecida, apesar de existirem fortes indícios de que esta seja uma doença de caráter hereditário nesta espécie (Gambardella et al., 1975, Withrow et al., 2013, Andersson, 2009), assim como em humanos e equinos (Gambardella et al., 1975, Pei et al., 2010, Fletcher, 2002, Withrow et al., 2013, Andersson, 2009).

A real incidência da ECM em cães é de difícil determinação (Withrow et al., 2013), mas sabe-se que a incidência em humanos é de 1:50.000 (Fletcher, 2002, Hameetman et al., 2004). Considerando características tais como raça, idade e local de origem dos pacientes apresentados, associadas à ocorrência, em ambos, de uma doença de baixa incidência e de provável caráter hereditário em cães, presume-se, então, que os dois animais possuam a mesma origem familiar.

A ECM apresenta características que permitem diagnóstico definitivo a partir de exame radiográfico (Gomes et al., 2007), como crescimentos ósseos pedunculados ou não, de tamanho variável, a partir da superfície óssea (Gambardella et al., 1975, Andersson, 2009) e cortical contínua à do osso subjacente (Gomes et al., 2007), sendo bem circunscritas e não apresentando lise óssea ou proliferação periosteal (Vanel et al., 2013), de contornos suaves e radiopacidade mista (Gambardella et al., 1975, Andersson, 2009).

As lesões podem se desenvolver de forma a provocar compressão medular (Gambardella et al., 1975, Withrow et al., 2013, Andersson, 2009) e raízes nervosas, levando a sinais neurológicos tais como fraqueza, ataxia, dismetria, propriocepção diminuída e paresia ou paralisia (Gambardella et al., 1975, Andersson, 2009), além de exercerem pressão sobre as estruturas de tecidos moles adjacentes (Gambardella et al., 1975, Gomes et al., 2007, Vanel et al., 2013, Andersson, 2009), provocando dor e prejudicando sua função (Gambardella et al., 1975, Withrow et al., 2013, Andersson, 2009).

\section{Material e Métodos}

CASO 1: Foi atendido no Hospital de Clínicas Veterinárias da Universidade Federal de Pelotas (HCV/UFPel), um cão fêmea, da raça Teckel, de quatro meses de idade, proveniente da cidade de Rio Grande, com histórico de dificuldade progressiva de locomoção dos membros pélvicos e aumento de volume no membro pélvico esquerdo distal (Figura 1).

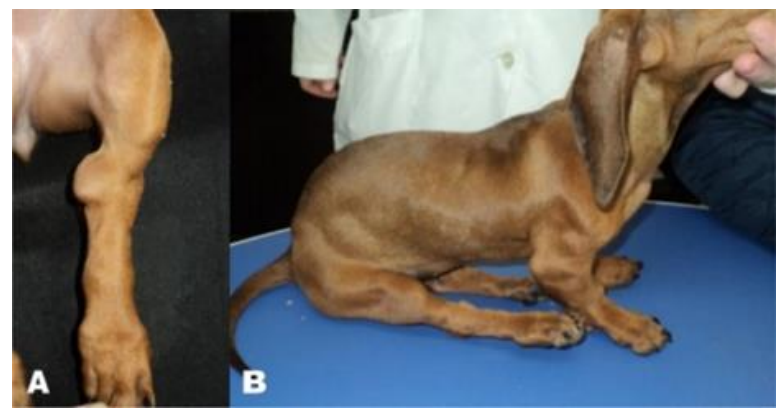

Figura 1. (A) Aumento de volume no membro pélvico esquerdo distal com (B) dificuldade progressiva de locomoção dos membros pélvicos.

Ao exame físico, o aumento de volume era indolor, firme, com consistência firme e localizava-se na região distal de tíbia e fíbula esquerdas. Havia perda da propriocepção generalizada, mais acentuada no membro pélvico direito, além de escoriações no dorso das falanges dos membros posteriores. Não foram evidenciadas alterações nos demais reflexos e, tanto o hemograma quanto o perfil bioquímico encontravam-se dentro dos padrões fisiológicos para a espécie. No exame radiográfico (Figura 2), evidenciou-se presença de massas, áreas nodulares adjacentes e contiguas ao osso, na metáfise distal do fêmur, proximal e distal da tíbia e proximal da 
fíbula esquerdas; além de estruturas semelhantes deformando os processos espinhosos de T3, T6 e T7 e na terceira costela direita, alterando o contorno e projetando-se para o interior da cavidade torácica. Com base nos exames radiográficos e avaliação clínica do paciente, firmou-se o diagnóstico de exostose cartilaginosa múltipla.

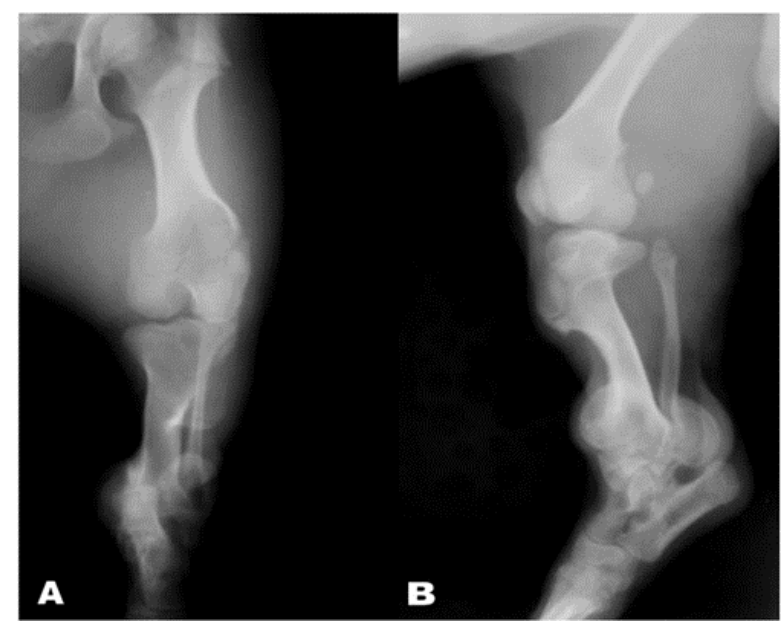

Figura 2. (A) Radiografia ventro-dorsal - Aumento de volume no membro pélvico esquerdo, (B) radiografia médiolateral - Nódulos adjacentes ao osso proximal e distal da tíbia e proximal da fíbula esquerda.

Foi estabelecido um protocolo analgésico com $2 \mathrm{mg} / \mathrm{kg}$ de cloridrato de tramadol e o acompanhamento clínico da paciente, pois, apesar de os nódulos serem indolores, o paciente apresentava desconforto muscular.

CASO 2: Dois meses após o atendimento do primeiro paciente, um segundo cão, macho, da raça Teckel, de 6 meses de idade, proveniente da cidade de Rio Grande, apresentando aumentos de volume nodulares de forma similar à descrita anteriormente (Figura 3), foi encaminhado ao Setor de Diagnóstico por Imagem do HCV/UFPel para realização de exame radiográfico dos membros pélvicos, pelve e tórax.

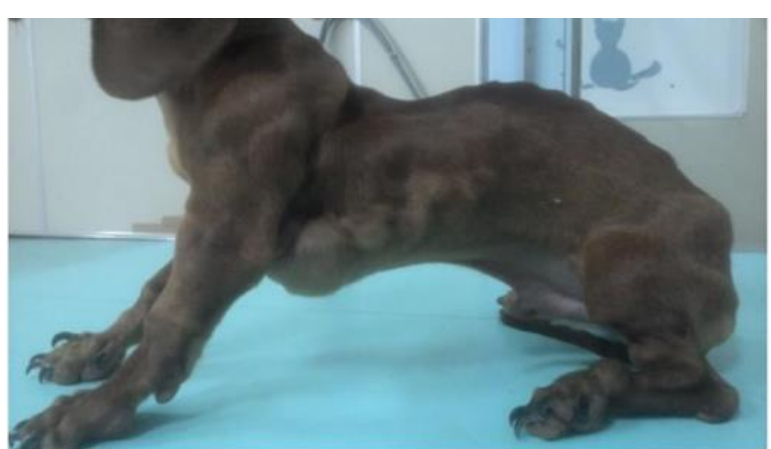

Figura 3. Áreas nodulares no tórax e membro pélvico esquerdo.
Foram observadas massas ósseas nodulares no ísquio e ílio direitos, e nas metáfises proximais de ambas as tíbias e distal da tíbia direita, além de alterações semelhantes em diversas costelas torácicas, projetando-se, tanto para a superfície externa do tórax, quanto para o interior da mesma, sugerindo exostose cartilaginosa múltipla. Por este paciente ter sido encaminhado ao Setor de Radiologia do HCV/UFPel por um médico veterinário não atuante na instituição, a conduta adotada após o exame radiográfico é desconhecida.

\section{Discussão}

A exostose cartilaginosa múltipla (ECM) consiste de projeções ósseas recobertas por cartilagem, originadas a partir da superfície óssea externa (Gambardella et al., 1975, Fletcher, 2002, Bovée, 2008, Andersson, 2009), sendo a cavidade medular contígua a do osso subjacente (Fletcher, 2002, Bovée, 2008) que pode se apresentar de forma solitária, sendo, então, denominada osteocondroma (Gomes et al., 2007).

Em medicina veterinária, a ECM é considerada uma alteração do desenvolvimento, que ocorre principalmente em animais em fase de crescimento. $\mathrm{O}$ crescimento das lesões cessa com a maturidade óssea (Hameetman et al., 2004, Withrow et al., 2013). Entretanto, são relatados casos atípicos, em que o surgimento das lesões que ocorrem após a maturidade óssea. As vértebras, costelas, escápulas, pelve e ossos longos são locais de predileção para o desenvolvimento das lesões (Gambardella et al., 1975, Andersson, 2009). A doença é descrita no homem, em cães, gatos e cavalos (Gambardella et al., 1975, Andersson, 2009), havendo também, na literatura científica, relato de sua ocorrência em um suíno.

A literatura acerca da ECM em cães é escassa. Acredita-se que é baixa a sua incidência e, ou como muitas vezes seu diagnóstico seja incidental, pois nem sempre apresenta sinais clínicos, não se sabe a real extensão (Withrow et al., 2013). É descrita em seres humanos, e 70\% está relacionado a mutações dos genes EXT1 e EXT2 (Pei et al., 2010), em cães estima-se esta possibilidade. Considerando raça, idade, sexo dos animais acometidos, a maioria dos casos relatados, é constituído por cães machos, jovens, destacamse os Terriers e seus cruzados como a raça de maior prevalência da doença, seguidos por Pastor de Sheteland, Poodles Toy, Dog Alemão, Boxer e 
Border Collie (Owen and Bostock, 1971, Doige, 1987, Krauser, 1990).

A ossificação pode ocorrer de duas formas: a ossificação intramembranosa (ou direta), e a ossificação endocondral (ou indireta), que é aquela que ocorre nos ossos passíveis de serem acometidos por ECM (Gambardella et al., 1975, Andersson, 2009). A ossificação intramembranosa ocorre na maioria dos ossos chatos e participa no crescimento dos ossos curtos e espessamento dos ossos longos. Ocorre diretamente a partir do tecido conjuntivo, sem a necessidade de um molde cartilaginoso do osso a ser formado. Um grupo de células se diferencia em osteoblastos e, posteriormente, em osteócitos, formando ilhas ósseas. Estes centros ósseos aumentam gradativamente, de forma a coalescerem, substituindo todo o tecido conjuntivo por tecido ósseo (Gambardella et al., 1975, Andersson, 2009). A ossificação endocondral ocorre em todos os ossos curtos e longos do organismo e sendo responsável pelo seu crescimento primário. $\mathrm{O}$ tecido ósseo é formado a partir de um molde de cartilagem hialina, de formato similar ao do osso final. O processo se inicia no centro de ossificação primária localizado na diáfise e, posteriormente, centros de ossificação secundários, localizados nas epífises (Gambardella et al., 1975, Andersson, 2009).

As lesões da exostose cartilaginosa múltipla ocorrem por processo de ossificação endocondral, a partir das placas epifisárias, durante a formação óssea (Withrow et al., 2013). A maneira como as protuberâncias ósseas ocorrem não está totalmente esclarecida. A teoria mais aceita, explica o surgimento das exostoses a partir de um fragmento de cartilagem da placa epifisária se desloca por um defeito no periósteo e sofre calcificação endocondral, o que resultaria numa orientação anormal do crescimento ósseo, dando origem às lesões (Gambardella et al., 1975, Gomes et al., 2007, Andersson, 2009). Outras teorias descrevem a causa como uma condrodisplasia na periferia da placa epifisária, mas também não há consenso sobre os mecanismos que levariam à condrodisplasia (Gambardella et al., 1975, Andersson, 2009).

Cães com ECM podem não apresentar sinal clínico, desta forma, o diagnosticado é incidental (Gambardella et al., 1975, Andersson, 2009). Geralmente, os animais apresentam uma massa palpável, não dolorosa, na superfície de um ou mais ossos (Withrow et al., 2013), e os sinais clínicos variam conforme o local e tamanho das massas (Andersson, 2009). As exostoses podem se desenvolver nas vértebras, provocando compressão medular (Andersson, 2009, Vanel et al., 2013, Withrow et al., 2013) e de raízes nervosas, levando a sinais neurológicos tais como dor, fraqueza, ataxia, dismetria, propriocepção diminuída e paresia ou paralisia (Andersson, 2009). Também podem exercer pressão sobre tendões, músculos, vasos e nervos (Gambardella et al., 1975, Gomes et al., 2007, Andersson, 2009, Vanel et al., 2013), provocando dor e prejudicando sua função (Andersson, 2009, Withrow et al., 2013). Podem ocorrer, ainda, deformidades ósseas alterando o eixo longitudinal dos ossos longos e fraturas, bem como a transformação sarcomatosa (Gomes et al., 2007, Andersson, 2009, Vanel et al., 2013). Tem-se que ECM não causa alterações no hemograma e bioquímica sérica cálcio, fósforo e fosfatase alcalina (Gambardella et al., 1975, Andersson, 2009). O estudo radiográfico é indicado; além de ser um recurso acessível e não invasivo. Esta técnica adquire papel fundamental para o estudo de todo o esqueleto e identificação de todas as possíveis alterações, Desta forma, sendo possível determinar o tamanho e a localização de cada uma delas, e posteriormente, ao acompanhamento de pacientes com ECM. Esta visão geral é necessária ao prognóstico, bem como anteriormente aos procedimentos cirúrgicos, para que nenhuma lesão seja negligenciada (Gambardella et al., 1975, Andersson, 2009).

As lesões apresentam características que são observadas claramente nas radiografias convencionais (Gomes et al., 2007), entretanto, para alterações na coluna vertebral, a mielografia assume papel importante na detecção de compressões subclínicas da medula espinhal (Andersson, 2009). No primeiro caso, apresentado sinais clínicos são condizentes a compressão de regiões raízes nervosas, nervos e musculatura pelas massas ósseas, comprimindo-os e, consequentemente, provocando dor e déficit proprioceptivo.

As alterações radiográficas podem ser ratificadas com métodos de imagem com capacidade tridimensional, como a tomografia computadorizada (TC) e a ressonância magnética (RM). Esses métodos são importantes na avaliação de ossos chatos, com anatomia complexa como a escápula, ou em vértebras e arcos costais (Gomes et al., 2007). Ao exame radiográfico, as exostoses apresentam crescimentos ósseos pedunculados ou não, de 
tamanho variável, a partir da superfície óssea (Gambardella et al., 1975, Andersson, 2009), apresentando uma cortical contínua à do osso subjacente (Gomes et al., 2007). Em ambos os casos relatados, as características radiográficas das lesões são consistentes com as descritas pela literatura. Essas lesões têm aparência benigna (Vanel et al., 2013, Withrow et al., 2013), sendo bem circunscritas e não apresentando lise óssea ou proliferação periosteal (Vanel et al., 2013), de contornos suaves e radiopacidade mista pela intercalação de áreas de densidade óssea e áreas de menor radiopacidade pela presença de cartilagem hialina, que apresenta radiodensidade similar à dos tecidos moles (Gambardella et al., 1975, Andersson, 2009). Quando localizadas nas costelas, tendem a apresentar contornos mais irregulares e uma combinação das diferentes radiopacidades de forma mais desestruturada, como o percebido no caso 2 , enquanto as alterações em vértebras e ossos longos, usualmente, possuem aparência mais organizada (Gambardella et al., 1975, Andersson, 2009).

A transformação maligna para condrossarcoma ou osteossarcoma pode ocorrer, podendo ser detectada na ressonância magnética (RM) e tomografia computadorizada (TC). Na TC, o osso apresenta um padrão desorganizado, com a porção cartilaginosa espessada e pobremente mineralizada. A espessura da porção cartilaginosa também pode ser medida com precisão na RM (Vanel et al., 2013). Radiograficamente, a perda dos contornos lisos, associada à lise e/ou proliferação óssea são indícios de transformação maligna (Andersson, 2009).

A lesão é composta por três camadas: pericôndrio, cartilagem e osso. A camada externa é um pericôndrio fibroso, contínuo ao periósteo do osso subjacente, seguido por uma porção cartilaginosa de até $2 \mathrm{~cm}$ de espessura. $\mathrm{Na}$ superfície desta porção cartilaginosa os condrócitos estão agrupados, enquanto os condrócitos localizados próximos à região de transição estão organizados em cordões e sofre ossificação endocondral, de forma a similar a uma placa de crescimento. Perda de arquitetura da cartilagem, áreas de extensa fibrose, alteração mixóide, alta celularidade condrocítica, atividade mitótica e necrose são características indicativas de transformação maligna secundária (Fletcher, 2002).

O tratamento somente se faz necessário quando as alterações afetam a função corporal do animal, como quando da presença de dor, movimentos prejudicados, distúrbios do crescimento e sinais clínicos neurológicos (Gambardella et al., 1975, Bovée, 2008, Andersson, 2009). Devendo ser tratada no caso de suspeita de transformação maligna. $\mathrm{O}$ tratamento é baseado na remoção cirúrgica do tecido alterado. Cães com ECM assintomática habitualmente não são tratados cirurgicamente, uma vez que as lesões não são dolorosas e geralmente param de crescer com a maturidade óssea. No entanto, a excisão precoce das lesões possui vantagens. Quando as lesões são pequenas, a intervenção é menos extensa, há menos lesão dos tecidos adjacentes e o risco de transformação maligna diminui (Gambardella et al., 1975, Andersson, 2009). A excisão da proliferação óssea geralmente é curativa (Fletcher, 2002). Cães com histórico de ECM devem ser cuidadosamente avaliados para malignidade óssea se os sinais clínicos retornarem ao longo de sua vida (Withrow et al., 2013). As recidivas podem ocorrer quando da excisão incompleta, porém, múltiplas recidivas ou a recidiva de uma lesão mesmo após sua completa excisão devem levantar suspeitas de malignidade (Fletcher, 2002).

Apesar de os osteocondromas serem alterações benignas, o prognóstico, costuma variar de ruim a reservado. Em diversos casos, cães acometidos por ECM são submetidos à eutanásia antes de completarem um ano de idade em consequência da evolução dos sinais clínicos (Gambardella et al., 1975, Andersson, 2009). Também, apesar de, em humanos, a taxa de transformação maligna seja de apenas $1 \%$ à $5 \%$ (Bovée, 2008), em cães, relata-se sua ocorrência em 5 de 6 cães que atingiram os 6 anos de idade (Andersson, 2009). O prognóstico deve ser considerado reservado para animais jovens que apresentem uma grande quantidade de lesões, não sendo possível prever o curso clínico dos nódulos que não forem excisados. Cães que estão próximos de atingir a maturidade óssea e apresentem somente sinais clínicos oriundos de lesões operáveis, bem como cães que já atingiram a maturidade óssea e não apresentam sinais clínicos tem um bom prognóstico (Andersson, $\underline{2009)}$.

Recorre-se ao tratamento cirúrgico quando há suspeita de transformação maligna (Andersson, 2009), bem como quando essas massas causam dor, sinais neurológicos, ou ainda prejudiquem a movimentação ou o crescimento do animal afetado (Bovée, 2008, Andersson, 2009). No cão do primeiro caso apresentado, apesar de o paciente apresentar dor e déficit proprioceptivo, optou-se 
por não realizar a excisão das lesões. No entanto, recomendou-se ao proprietário realizar o acompanhamento periódico do quadro junto ao médico veterinário, possibilitando a modificação da conduta adotada conforme necessário.

\section{Conclusão}

Sempre que se constatem aumentos de volume de consistência firme em cães jovens, inclusive os da raça Teckel, como aqui apresentados, se faz necessário um minucioso exame para que se constate ou não exostose cartilaginosa múltipla como a causa. Sendo que para o estabelecimento do diagnóstico e a escolha de um protocolo terapêutico, o exame radiográfico se mostrou imprescindível nos casos aqui apresentados.

\section{Referências Bibliográficas}

Andersson, A. C. 2009. Multiple cartilagenous exostoses in the dog. The European Journal of Companion Animal Practice, 19, 61-66.

Bovée, J. V. M. G. 2008. Multiple osteochondromas. Orphanet Journal of Rare Diseases, 3, 1-7.

Doige, C. E. 1987. Multiple cartilaginous exostoses in dogs. Veterinary Pathology, 24, 276-278.

Fletcher, C. D. M. U. 2002. Pathology and genetics of tumors of soft tissue and bone. World Health Organization Classification of Tumors, 4, 35-46.

Gambardella, P. C., Osborne, C. A. \& Stevens, J. B. 1975. Multiple cartilaginous exostoses in the dog. Journal of the American Veterinary Medical Association, 166, 761-768.

Gomes, F. S. E., Lewin, F., Mariotti, G. C., Cruz, R. O., Baptista, P. P. R., Yonamine, E. S., Próspero, J. D., Capasso Filho, M. \& Yamaguchi, C. K. 2007. Osteocondromas: avaliação por imagem das complicações. Revista Imagem, 29, 53-59.

Hameetman, L., Bovée, J. V. M. G., Taminiau, A. H. M., Kroon, H. M. \& Hogendoorn, P. C. W. 2004. Multiple osteochondromas: clinicopathological and genetic spectrum and suggestions for clinical management. Hereditary Cancer in Clinical Practice, 2, 161173.

Krauser, K. 1990. Multiple enchondromatosis in dogs. Pathologico-anatomic and histologic findings, discussion of pathogenesis. Tierarztliche Praxis, 18, 301-307.

Owen, I. N. \& Bostock, D. E. 1971. Multiple cartilaginous exostoses with development of a metastasizing osteosarcoma in a Shetland sheepdog. Journal of Small Animal Practice, 12, 507-512.

Pei, Y., Wang, Y., Huang, W., Hu, B., Huang, D., Zhou, Y. \& Su, P. 2010. Novel mutations of EXT1 and EXT2 genes among families and sporadic cases with multiple exostoses. Genetic Testing and Molecular Biomarkers, 14, 865-872.

Vanel, M., Blond, L. \& Vanel, D. 2013. Imaging of primary bone tumors in veterinary medicine: Which differences? European Journal of Radiology, 82, 2129-2139.

Withrow, S. J., Page, R. \& Vail, D. M. 2013. Withrow and MacEwen's Small Animal Clinical Oncology-E-Book. Elsevier Health Sciences, St. Louis Missouri.

\section{Article History:}

Received 4 July 2017

Accepted 10 August 2017

Available on line 18 October 2017

License information: This is an open-access article distributed under the terms of the Creative Commons Attribution License 4.0, which permits unrestricted use, distribution, and reproduction in any medium, provided the original work is properly cited. 